\title{
African indigenous knowledge and research
}

\begin{tabular}{|c|c|}
\hline \multicolumn{2}{|c|}{$\begin{array}{l}\text { Authors: } \\
\text { Frances E. Owusu-Ansah }{ }^{1} \\
\text { Gubela Mji }\end{array}$} \\
\hline \multicolumn{2}{|c|}{$\begin{array}{l}\text { Affiliations: } \\
\text { 1Department of Behavioural } \\
\text { Sciences, Kwame Nkrumah } \\
\text { University of Science and } \\
\text { Technology, Ghana }\end{array}$} \\
\hline \multicolumn{2}{|c|}{$\begin{array}{l}{ }^{2} \text { Centre for Rehabilitation } \\
\text { Studies, University of } \\
\text { Stellenbosch, South Africa }\end{array}$} \\
\hline \multicolumn{2}{|c|}{$\begin{array}{l}\text { Correspondence to: } \\
\text { Frances Owusu-Ansah }\end{array}$} \\
\hline \multicolumn{2}{|c|}{$\begin{array}{l}\text { Email: } \\
\text { feoansah@yahoo.com }\end{array}$} \\
\hline \multicolumn{2}{|c|}{$\begin{array}{l}\text { Postal address: } \\
\text { School of Medical Sciences, } \\
\text { Kwame Nkrumah University } \\
\text { of Science and Technology, } \\
\text { PO Box KS 99, Kumasi, } \\
\text { Ghana, West Africa }\end{array}$} \\
\hline \multicolumn{2}{|c|}{$\begin{array}{l}\text { Dates: } \\
\text { Received: } 13 \text { Apr. } 2012 \\
\text { Accepted: } 05 \text { Oct. } 2012 \\
\text { Published: } 16 \text { Jan. } 2013\end{array}$} \\
\hline \multicolumn{2}{|c|}{$\begin{array}{l}\text { How to cite this article: } \\
\text { Owusu-Ansah, F.E. \& Mji, G., } \\
\text { 2013, 'African indigenous } \\
\text { knowledge and research', } \\
\text { African Journal of Disability } \\
\text { 2(1), Art. \#30 } 5 \text { pages. http:// } \\
\text { dx.doi.org/10.4102/ajod. } \\
\text { v2i1.30 }\end{array}$} \\
\hline \multicolumn{2}{|c|}{$\begin{array}{l}\text { Copyright: } \\
\text { (C) 2013. The Authors. } \\
\text { Licensee: AOSIS } \\
\text { OpenJournals. This work } \\
\text { is licensed under the } \\
\text { Creative Commons } \\
\text { Attribution License. }\end{array}$} \\
\hline \multicolumn{2}{|c|}{ Read online: } \\
\hline 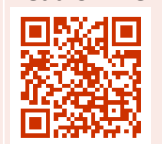 & $\begin{array}{l}\text { Scan this QR } \\
\text { code with your } \\
\text { smart phone or } \\
\text { mobile device } \\
\text { to read online. }\end{array}$ \\
\hline
\end{tabular}

This paper seeks to heighten awareness about the need to include indigenous knowledge in the design and implementation of research, particularly disability research, in Africa. It affirms the suitability of the Afrocentric paradigm in African research and argues the necessity for an emancipatory and participatory type of research which values and includes indigenous knowledge and peoples. In the predominantly Western-oriented academic circles and investigations, the African voice is either sidelined or suppressed because indigenous knowledge and methods are often ignored or not taken seriously. This paper posits that to be meaningful and empowering, African-based research must, of necessity, include African thought and ideas from inception through completion to the implementation of policies arising from the research. In this way the work is both empowering and meaningful for context-specific lasting impact.

\section{Introduction}

The thrust of this paper is to heighten awareness, stimulate new thoughts and generate discussion on the wealth of indigenous knowledge. African researchers need to persist in developing and using alternative methods of studying our reality and refrain from sticking to the research pathways mapped out by Western methodologies, within which many have been trained. Whilst it neither seeks to negate nor denigrate known Western methods of investigation, it intends to challenge researchers and African scholars in particular into alternative methods of inquiry as far as the investigation and preservation of indigenous knowledge is concerned for the development and empowerment of African peoples and particularly persons with disabilities.

Knowledge or science, and its methods of investigation, cannot be divorced from a people's history, cultural context and worldview. Worldview shapes consciousness and forms the theoretical framework within which knowledge is sought, critiqued and or understood (Sarpong 2002). Almost all knowledge has cultural relevance and must be examined for its particular focus. From this perspective it is dangerous, if not oppressive, to hail any one method of investigation as universal (Asante 1987). According to Asante, the hallowed concepts and methods within Western thought are inadequate to explain all of the ways of knowing because 'universality can only be dreamed about when we have "slept" on truth based on specific cultural experiences' (Asante 1987:168). Therefore, he argues that all cultures and the indigenous ways of knowing arising from them are to be respected and valued in their uniqueness. Although still inchoate, it is most gratifying to see that some African scholars (Tanyaniwa \& Chikwanha 2011; Ntumngia 2009; Pence \& Nsamenang 2008; Nsamenang 2006; Mkabela 2005; Mpofu 2002; Mpofu 1994) have taken on the important yet daunting task of making relevant to the African reality, Western theories and constructs believing that African knowledge has much to enrich existing Western knowledge and methodologies.

African knowledge and methods of knowing have yielded results and contributions that have been discounted by many and even sometimes by the African scholars (Nsamenang 1995). Contributions made by Africa and her people to history and civilisation are conspicuously missing from text books for formal education and generally remain unknown to many (Ngara 2007). Silenced contributions from ancient Egyptian education to philosophy, mathematics, architecture, medicine (Bargblor 2003) and library science (Zulu 2008) are just a few. A quick review of the literature reveals that Africa has historically made a host of contributions to world civilisation (Asante 1990; Derricourt 2011) which remain unknown and subliminally perpetuate the myth that African and or traditional African societies are incapable of rigorous scientific inquiry.

\section{Characteristics of African indigenous knowledge}

Indigenous knowledge or African knowledge, here used interchangeably, is experiential knowledge based on a worldview and a culture that is basically relational. The spirit of the 
African worldview includes wholeness, community and harmony which are deeply embedded in cultural values. A person becomes human only in the midst of others and seeks both individual and collective harmony as the primary task in the process of becoming a true person (Sarpong 2002; Sarpong 1991). Like its peoples, acquisition of knowledge is collective and community oriented. Central to the African worldview is the strong orientation to collective values and harmony rooted in a collective sense of responsibility - a 'collective ethic' which acknowledges that survival of the group derives from harmony through interdependence and interconnectedness (Mkabela 2005; Sarong 2002; Sarpong 1991).

A helpful example comes from a South African colleague who engaged rural indigenous women by means of focused group discussions in her quest to understand the concept of health from an indigenous perspective. She learned that for the rural indigenous women of Southern Africa health was basically about relationships! They believed that ill health occurred when relationships have broken down. In their indigenous thinking, even when restoration to health is sought through the biomedical approach, wholeness was possible only when broken relationships have been mended and restored because a person is most healthy when she or he is in harmony with others! (Durie 2004).

African knowledge, and its method of acquisition, has a practical, collective and social or interpersonal slant. The works of Mpofu (2002) and Nsamenang (2006) show that indigenous conceptions of intelligence, for example, emphasise the practical, interpersonal and social domains of functioning and are quite differentiated from the cognitive 'academic' intelligence that dominates Western concepts of the construct. Likewise, learning for the African child is mostly peer oriented and participatory with less adult instruction (Nsamenang 1995; Nsamenang 2006; Pence \& Nsamenang 2008) which is consistent with a generally collective African self-concept (Mpofu 1994).

As a knowledge system, it is characteristically oral and passed on from generation to generation in the context of community living and activities (Sarpong 1991; Mkabela 2005). Considering that culture is the 'lens' through which a person perceives, interprets and makes sense of his or her reality, if we speak of the inclusion of African indigenous knowledge in any investigation, we would be speaking about the examination of African reality from the perspective of the African and not with the African on the periphery.

However, oral tradition, characteristic of indigenous knowledge systems is often, although erroneous, looked down upon relative to the written tradition. Partly because indigenous knowledge is mainly oral and not written, and partly because it is people-centered and sometimes not so easily 'measurable' (Emeagwali 2003), it has been mistaken by many as simplistic and not amenable to systematic scientific investigation. However, its rich complexities are found in the community ceremonies and rituals, namely, story-telling, proverbs, folktales, recitation, demonstration, sport, epic, poetry, reasoning, riddles, praise, songs, word games, puzzles, tongue-twisters, dance, music, and other education-centered activities (Ngara 2007).

It is prudent to say that African indigenous knowledge is not without limitations. Some of these are the tenacious continuity of practices and beliefs that lack openness and flexibility to necessary or constructive changes. There is a tendency to forget that, just as any other type of knowledge, it is subject to change from economic, environmental and social forces (Tanyanyiwa \& Chikwanha 2011) and therefore its acceptance must be subject to critical observation and analysis. However, limitations notwithstanding, before the advent of Western methods of scientific inquiry African knowledge and methods have successfully guided its peoples in all spheres of functioning, including the spiritual, social, educational, agricultural, political and economic (Tanyanyiwa \& Chikwanha 2011; Ntumngia 2009; Pence \& Nsamenang 2008; Pence \& Marfo 2008; Nsamenang 2006; Mpofu 2006; Zulu 2006; Levers 2006; Emeagwali 2003; Sarpong 2002; Nsamenang \& Lamb 1995; Sarpong 1991; Asante 1987). It is from this perspective that the authors are of the view that African knowledge and methods of knowing must drive African research if it is to be meaningful to its peoples.

\section{Afrocentric methodology and disability research in Africa}

Authors affirm that Asante's Afrocentric method arising from his works (Asante 1987; 1988; 1990), termed 'Afrocentricity', would be an appropriate complement to qualitative methodology in disability research in an African context because the philosophical and theoretical paradigm underlying Afrocentricity is consistent with the African worldview. Afrocentricity is a paradigm that has at its core the understanding of the African identify as rooted, centred and located in the African culture in all aspects - spiritual, social, political and economic. It is the examination of the African reality from the perspective of the African; one that places the African experience at the core, recognises the African voice and reaffirms the centrality of cultural experience as the place to begin to create a dynamic multicultural approach to research (Mkabela 2005).

It is noteworthy that Afrocentricity is not just about Africa or the African culture. Instead, its fundamental aim is that all cultural centres must be respected and not impaired by colour or geography. Instead, to be 'centred' is to be located as an agent, not as 'the other' (Mkabela 2005), the basis of which is equal and respectful mutual exchange and synthesis of information. To this end, Afrocentricity encourages cultural and social immersion as opposed to scientific distance in research as well as the use of tools and methods indigenous to the people being studied. This way, indigenous peoples are active participants in the articulation of the views, wishes, concerns and research questions that they deem important to their cultural context and experience. Social immersion would 
provide researcher knowledge about and familiarity with the history, language, philosophy, and myths of the people under study, and reduce misinterpretation, perpetuation of myths and researcher imposition (Mkabela 2005).

In effect, the Afrocentric paradigm does not only advocate cultural immersion, indigenisation of tools and methods of investigation that African peoples can use to make sense of their own realities but also the interpretation of research data from an indigenous African perspective. Succinctly put:

This means that the method differs markedly in its reflexive sensitivity to its data and the manner in which it analytically explores the data. The aim is to be sufficiently detailed and sensitive to actual social contexts and to investigate the methodological bases or orderly character of ordinary social activities. This means that the researcher should understand that what $\mathrm{s} /$ he does and how s/he does it is specific to the culture (a situated response), the problem, and dynamics of the particular context. To achieve the understanding of this cultural framework requires indigenous African people's involvement and control of research (Mkabela 2005:181)

This 'participatory' approach allows professionals to learn with, by and from indigenous communities and to create a working relationship in which people's priorities and values become more fully expressed in research. The indigenous communities within which research is conducted are not treated as 'informants' but 'significant participants' and as 'equals' in both the process of research and the decisionmaking processes that bring about policy changes which affect their communities (Mkabela 2005). More importantly, a research methodology that is collaborative emphasises and strengthens the African value of collective responsibility and affirms the centrality of African indigenous ideals and values as legitimate frames of reference for conducting research, from data collection to analysis and implementation.

Afrocentric and qualitative methods are similar and complementary as both assume the use of interpretative schemes that must be understood and have the character of the local context articulated. However, core to the Afrocentric paradigm as already articulated, is the position that to be Afrocentric, research must involve indigenous people in all aspects and stages, from beginning to the end, and must be unique to the social structure and cultural values of African indigenous communities. It encourages a spiral methodology of data collection - community, participants, researchers and decision-makers all interacting in a synergistic and bidirectional manner (Mkabela 2005), consistent with the African value of oneness.

Therefore, for meaningful African-based disability research, it is important that the African view is not discounted because learning does not take place in a vacuum. True learning, and indeed adult learning, occurs when the learner relates new material to existing ones. The African culture, with its relational values and emphasis, is the milieu within which the African learns best and makes sense of her or his world. The African can make contributions to the world by understanding and being grounded in its own knowledge system vis-a-vis those of others because 'true education' is when one has learned one's own as well as those of others.

That is why it is important that the African scholar, researching in Africa, particularly those trained outside of Africa or trained in Western-oriented methodologies, reacquaint themselves with their own African knowledge systems. The 'Western educated' African, knowledgeable in Western concepts and methods, may be alienated from self because of a lack of adequate knowledge about his or her own culture and indigenous knowledges and or self-imposed emulation of foreign ways of knowing and being. He or she may, therefore, be crippled in the ability to indigenise Western acquired knowledges and skills within the African cultural context (Nsamenang 1995). It is not surprising that a tendency to adhere to Western tools and methodologies in African research is one hurdle in the process of the indigenisation and integration (Azuma 1984) of disciplines from African perspectives (Mpofu 2002; Nsamenang 1995).

Undoubtedly, there are many challenges in the process of indigenising science and research in Africa, given the predominance of Western constructs in science (Azuma 1984) and the lack of respect and recognition for indigenous methods as valid forms of knowledge (Nsamenang 1995). In addition to this are the constraints and difficulties of publication in reputable international journals for African scholars and the general assumption that one form of knowledge is better than the other and that for indigenous knowledge to be true and relevant it has to follow Western methods and ways of knowing.

One may ask: is research in Africa unique? Why and how is the Afrocentric method and its embedded process of indigenisation essential to disability research in Africa? How can disability research in Africa maintain its own unique identity whilst embracing Western methodologies? The position of this paper is that research in Africa, in general, is unique because of uniqueness of culture. That is not to say that it is so unique as to be completely divorced from all other human experiences and knowledge. Uniqueness, as used here, is meaningful in the context of the African experience and worldview which is arguably different from those of the Western world. If so, how do we preserve the endangered indigenous knowledge and the communal contexts within which this knowledge is nurtured and passed on? How, for example, can the African scholar return to her or his roots to facilitate the preservation of African knowledge systems, for the inclusion of African ways of knowing into existing 'mainstream' knowledge systems, the failure of which alienates the African from self and community? We acknowledge that these are questions with neither easy nor ready-made answers. They are raised to stimulate ideas and discussions on the way forward.

Basically, this paper affirms suitability of a participatory research methodology such as proposed in the Afrocentric paradigm for disability research in Africa because there are issues related to disability that are uniquely African. For 
example, the highest number of persons with disability is the poor and marginalised who are concentrated in low-income countries such as those on the African continent which also has the largest number of the world's poorest peoples (Mitra, Posarac \& Vick 2011). Therefore, poverty and disability are unfortunately home to Africa.

The notion of understanding disability has been an evolving concept in that disability results from the interaction between persons with impairments and attitudinal and environmental barriers that hinder their full participation in society on an equal basis with others (UN 2006). From this perspective, disability is no longer viewed as an individual tragedy but rather as a form of oppression in which people with impairments are disabled by multiple barriers of discrimination and social exclusion (Danso, Owusu-Ansah \& Alorwu 2012). Albert \& Harrison (2006) quoting Yeo (2001) reiterate this concern about disability research:

Traditional research often involves wealthy non-disabled outsiders questioning people about their lives. This is not a reliable way of getting information where there are big power differences and where questioners are not trusted friends. To get consent is not sufficient, as few people in situations of poverty and exclusion will refuse to be questioned by people with more power and authority. It is therefore essential that disabled people are fully involved in future research, including setting the agenda. (p. 14)

With regard to disability research, African persons with disability carry a double burden of exclusion by virtue of the neglect of African ways of knowing and also by being persons with a disability. Persons with disability are calling for society to stop perceiving them as objects of pity but as capable individuals who are contributing immensely to the development of society, including disability research. On the other hand, research within a social model of disability recognises the interaction of impairment with the social conditions that construct disability. Modern African scholars have this perception about the response of society towards vulnerable groups and the person with disability (Mbeki 1997):

Among the yardsticks by which to measure a society's respect for human rights, to evaluate the level of its maturity and its generosity, is by looking at the status that it accords to those members of society who are most vulnerable, disabled people, the senior citizens and its children (p. i).

Within this understanding, research that claims to be objective and neutral is inadequate if it does not challenge social oppression. Rather, a participatory and emancipatory research paradigm, such as the Afrocentric method, is called for with the goal being to:

... understand how the [oppression] of disabled people happens and discover ways to challenge it. The key to unlocking this process of transformation lies in the knowledge and life experience of disabled people themselves. This is why like indigenous ways of knowing they need to take the lead at all stages of the research process (Albert 2006:30).

Barnes (2008) identifies an emancipatory research agenda based on the social model as having the following features:
- It exposes disabling barriers in society and points toward change.

- It is accountable to disabled people through the research process, including the control and dissemination of the research product.

Within this framework, capacity building is seen as a twoway process whereby persons with disability expand researchers' knowledge of disability and at the same time themselves acquire valuable research skills.

More importantly, total inclusion of indigenous persons with disabilities in research based on mutual respect, such as suggested by the Afrocentric method, solidifies participants' own definition of self-determination and empowerment. Fostering self-esteem and empowerment are particularly important in disability research because of the close link between disability and poverty (Mitra et al. 2011). Disability, made worse by poverty, robs people of their dignity and sense of self. In a situation such as this, research that simply treats participants as 'outsiders' can only fuel an already eroded and fragile sense of self.

\section{Conclusion}

In conclusion, reiterating earlier points, proposing the Afrocentric methodology for disability research in a way that is both participatory and emancipatory does not by any means negate Western methodology. Instead, in the African wisdom of openness expressed in the proverb 'the river is flooded by tributaries', we dare say that to get a more complete and realistic understanding of the world we need to value all the available alternate ways of knowing and investigating (i.e. that of Africa and those of others) to jumpstart the African intellect and imagination towards rich, indigenous African-centred research.

The critical issue here for Africans scholars, who have mostly been educated outside Africa, is to find creative ways of using our rich cultural heritage and multilayered knowledge systems to understand our own reality and to empower our people; to pioneer and churn out African-centred research that empowers, liberates and reduces all shades of poverty, particularly the poverty of voicelessness amongst persons with disabilities. Thus emboldened, we can take our rightful place in the globalised world, a world that would be challenged to accept that 'one size does not fit all' and that all forms of knowledge are valid and valuable. The world needs to revise its impression that one can only be a researcher if one has undergone formal education because:

We were all born as researchers; research is the creating element that runs through our minds, bodies and feelings to guide, protect, and assist us to move to the next level of creation. Without research, human beings would quickly or slowly approach their extinction (Mji 2009:7).

Indigenous persons with disability in Africa, even the illiterate, do have something to contribute to the process of knowledge acquisition. Indigenous African knowledge is vulnerable because many of the carriers of this knowledge are 
dying without the documentation of these knowledges. To preserve such knowledges, a new path must be charted and a paradigm shift is imperative. It must be neither negating of existing Western methods of investigation nor polarised in outlook because that would undermine opportunities for the creation and generation of new knowledge, but must seek to respect all forms and sources of knowledge.

This paper advocates room for alternative ways of exploring and knowing so that there is no imposed one way to investigate. Each methodology, however seemingly different, can add value and enhance the process of creation of new knowledge as each brings insights and tools on how to perceive and interpret the world. In effect, this paper is primarily calling that the African ways of enquiry be used as the cornerstone for the process of research within the African cosmology and secondarily for it to be integrated into the global stage as part of the knowledge of the people of the world because it is time for the African voice to be heard!

\section{Acknowledgments Competing interests}

The authors declare that they have no financial or personal relationship(s) which may have inappropriately influenced them in writing this article.

\section{Authors' contributions}

Both authors conceptualised the paper. F.E.O.A. (Kwame Nkrumah University of Science and Technology) and G.M. (University of Stellensbosch) prepared and edited the manuscript for publication.

\section{References}

Albert, B., 2006, Lessons from the Disability, Knowledge and Research (KaR) Programme, Department for International Development, Overseas Development Group and Health link, London.

Asante, M.K., 1987, The Afrocentric idea, Temple University Press, Philadelphia.

Asante, M.K., 1988, Afrocentricity, Africa World Press, Trenton, NJ.

Asante, M.K., 1990, Kemet, Afrocentricity, and knowledge,: Africa World Press, Trenton, NJ.

Azuma, H., 1984, 'Psychology in a non-western country', International Journal of Psychology 19, 45-55. http://dx.doi.org/10.1080/00207598408247514

Bargblor, Z.E., 2003, Africa's contribution to contemporary western civilization, The Perspective, Atlanta, Georgia.

Barnes, C., 2008, 'An ethical agenda in disability research: Rhetoric or reality?', in D.M. Mertens \& P.E. Ginsberg (eds.), The Handbook of Social Research Ethics, pp. 458-473, Sage, London.

Danso, A.K., Owusu-Ansah, F.E. \& Alorwu, D., 2012, 'Designed to deter: Barriers to facilities at second cycle institutions in Ghana', African Journal of Disability 1(1) Art. \#2, 9 pages. doi:http://dx.doi.org/10.4102/ajod. v1i1.2. http://dx.doi. org/10.4102/ajod.v1i1.2
Derricourt, R.M., 2011, Inventing Africa: History, archaeology and ideas, Pluto Press, New York.

Durie, M., 2004, 'Understanding health and illness: Research at the interface between science and indigenous knowledge', International Journal of Epidemiology 33(5), 1138-1150. http://dx.doi.org/10.1093/ije/dyh250

Emeagwali, G., 2003, 'African indigenous knowledge systems (AIK): Implications for the curriculum', in T. Falola (ed.), Ghana in Africa and the world: Essays in honour of AduBoahen, Africa World Press, New Jersey.

Levers, L.L., 2006, 'Samples of indigenous healing: Path of good medicine', International Journal of Disability, Development and Education 53(4), 479-488. http://dx.doi.org/10.1080/10349120601008720

Mbeki, T., 1997, in Office on the Status for Disabled People (OSDP), South African Integrated National Disability Strategy White Paper.

Mitra, S., Posarac, A. \& Vick, B., 2011, 'Disability and poverty in developing countries: A snapshot from the World Health Survey', Human Development Network, 1-285. http://dx.doi.org/10.2139/ssrn.1908128

Mji, G., 2009, In Doing disability research: A practical guide to disability research in Africa, The Secretariat of the African Decade for Persons with Disabilities, Cape Town South Africa.

Mkabela, Q., 2005, 'Using the Afrocentric method in researching indigenous African culture', The Qualitative Report 10(1), 178-189.

Mpofu, E., 2002, 'Indigenization of the psychology of human intelligence in SubSaharan Africa', in W.J. Lonner, D.L. Dinnel, S.A. Hayes, \& D.N. Sattler (eds.), On-line Readings in Psychology and Culture (Unit 5, Chapter 2), (http://www. Wwu.edu/ culture), Center for Cross-Cultural Research, Western Washington wwu.edu/ culture), Center for Cross-Cultur
University, Bellingham, Washington, USA.

Mpofu, E., 2002, 'Psychology in sub-Saharan Africa: Challenges, prospects and promises', International Journal of Psychology 37(3), 179-186. http://dx.doi. org/10.1080/00207590244000061

Mpofu, E., 2006, 'Majority health care traditions intersect indigenous and complementary and alternative medicine', International Journal of Disability, Development and Education 53(4), 375-379. http://dx.doi. org/10.1080/10349120601008340

Mpofu, E., 1994, 'Exploring the self-concept in an African culture', Journal of Genetic Psychology 155(3), 341-354. http://dx.doi.org/10.1080/00221325.1994.9914784

Nsamenang, A.B., 2006, 'Human ontogenesis: An indigenous African view on development and intelligence', International Journal of Psychology 41(4), 293297.

Nsamenang, A.B., 1995, 'Factors influencing the development of psychology in subSaharan Africa', International Journal of Psychology 30(6), 729-739. http://dx.doi. org/10.1080/00207599508246598

Ngara, C., 2007, 'African ways of knowing and pedagogy revisited', Journal of Contemporary Issues in Education 2(2), 7-20.

Ntumngia, R.N. 2009, 'Uncovering farmers' ethnobotanical knowledge: A methodology for assessing farmers' perceptions of cassava varieties', African Crop Science Conference Proceedings 9, 467-473.

Pence, A. \& Nsamenang, B., 2008, A case for early childhood development in subSaharan Africa, Working Paper No. 51, Bernard van Leer Foundation, The Hague, Netherlands.

Pence, A. \& Marfo, K. 2008, 'Early childhood development in Africa: Interrogating constraints of prevailing knowledge bases', International Journal of Psychology 43(2), 78-87. http://dx.doi.org/10.1080/00207590701859143

Pokrant, B., 2006, Humanities postgraduate seminar: Ways of knowing in the social sciences, Social Sciences Program, Media, Society and Culture.

Sarpong, P., 1991, Ghana in retrospect: Some aspects of the Ghanaian culture, African Books Collective Ltd., Ghana.

Sarpong, P., 2002, Peoples differ: An approach to inculturation in evangelization, SubSaharan Publishers.

Tanyanyiwa, V.I. \& Chikwanha, M., 2011, 'The role of indigenous knowledge systems in the management of forest resources in Mugabe area, Masvingo, Zimbabwe', Journal of Sustainable Development in Africa 3(3), n.p.

UDS, UMSS, FRLHT, COMPAS, 2011, 'Learning together: Developing inclusive knowledges and sciences', vol. 1: Experiences and concepts in endogenous developments, research and education captured.

United Nations, 2006, Convention on the rights of Persons with Disabilities, viewed 02 September 2008, from http://www.un.org/disabilities/

Zulu, I.M., 2006, 'Critical indigenous African education and knowledge', The Journal of Pan African Studies 1(3), n.p.

Zulu, I.M., 2008, The ancient Kemetic roots of library and information science, Center for Afro-American Studies, University of California Los Angeles. 